\title{
Effective Average Correlation Factor and Excess Permittivity for Dielectric Studies on Binary Systems of Phthalates with Alcohols and Nitriles
}

\author{
RM. Umamaheshwari ${ }^{*}$, K. Sathish kumar $^{2,}$ M. Subramanian ${ }^{3}$ \\ ${ }^{1}$ Dept. of Physics, Sree Sevugan Annamalai College, Devakottai, Tamilnadu, India \\ ${ }^{2}$ Dept. of Physics, Sree Sevugan Annamalai College, Devakottai, Tamilnadu, India \\ ${ }^{3}$ Fatima Michael College of Engg. \& Tech., Madurai, Tamilnadu, India \\ *Corresponding Author: uma.ssac69@gmail.com,Tel.: +918825981697
}

Available online at: www.isroset.org

Received: 28/Oct/2018, Accepted: 07/Dec/2018, Online: 31/Dec/2018

\begin{abstract}
The determination of the structure and properties of associated liquids could provide deeper insight into the phenomenon of the molecular interactions and is of great importance in biology and chemical physics. Dielectric constant measurements have been extensively used to obtain the electric dipole moment of molecules with the object of determining the polarities of their bonds, geometrical structures of the molecules and significant shifts of the electric charge in them. Dielectric parameters such as Kirkwood correlation factor, effective correlation factor, corrective correlation factor and thermo dynamical excess parameters for a mixture of diethyl phthalate with isobutanol and benzonitrile were determined at $303 \mathrm{k}, 313 \mathrm{k}$ and 323 $\mathrm{k}$. The results were interpreted accordingly.
\end{abstract}

Keywords- Dielectric constant, Kirkwood correlation, Effective correlation, Phthalates, Isobutanol, Benzonitrile

\section{INTRODUCTION}

The electric permittivity often called the dielectric constant is a characteristic quantity, which can be easily measured. Dielectric constant measurements have been extensively used to obtain the electric dipole moment of molecules with the object of determining the polarities of their bonds, geometrical structures of the molecules and significant shifts of the electric charge in them. The calculation of molecular dipole moment from the measured dielectric constant of the bulk material depends upon the molecular interactions with their neighbors.

When an electric field acts on a molecule, it shifts to form an induced dipole, usually much smaller than the permanent dipole due to structural symmetry of the molecule. The dipole moment values are in the order of debye. Debye had related the dielectric constant and dipole moment with the molar polarization. But Debye's theory could be applied only to gaseous molecules. But Smyth had determined the dipole moment of dilute solutions of non-polar solvents to reduce the effects of internal field in the liquids. Onsagar equation related the dipole moment and dielectric constant for pure liquids. But this model was found to be applicable only for non-associative pure liquids.

\section{RELATED WORK}

\section{A. STATISTICAL MECHANICAL} CONSIDERATRIONS OF STATIC DIELECTRIC CONSTSNT AND ' $g$ ' FACTOR

Consider a macroscopic cavity of volume $\mathrm{V}$ containing $\mathrm{N}$ molecules. Let $\mathrm{E}_{0}$ be the mean macroscopic field due to the electric charges outside this volume, then the mean moment $\left.<\mathrm{M}_{\mathrm{E}}\right\rangle$ at the volume in the direction of the field is given by

$$
\left\langle\mathrm{M}_{\mathrm{E}}\right\rangle=\frac{\int \ldots \int \mathrm{M}_{\mathrm{E}} \exp \left(-\mathrm{U}\left(\mathrm{X}_{1} \mathrm{E}_{0}\right) / \mathrm{KT}\right) \mathrm{dx}}{\int \ldots \int \exp \left(-\mathrm{U}\left(\mathrm{X}_{1} \mathrm{E}_{0}\right) / \mathrm{KT}\right) \mathrm{dx}}
$$

where $\left\langle\mathrm{M}_{\mathrm{E}}\right\rangle$ is the moment associated with the given volume $\mathrm{V}$. $\mathrm{U}\left(\mathrm{X}, \mathrm{E}_{0}\right)$ is the total potential energy of $\mathrm{N}$ particles and $\mathrm{X}$ is a set of co-ordinates allowing a complete description of the system. The energy $U$ depends on all the interactions of all the particles with one another and also with the field $\mathrm{E}_{\mathrm{o}}$ and can be written as

$$
\mathrm{M}=\sum_{\mathrm{i}}\left[\mu_{\mathrm{i}}+\alpha\left(\mathrm{E}_{0}-\sum_{\mathrm{k}} \mathrm{T}_{\mathrm{ik}} \mathrm{m}_{\mathrm{k}}\right)\right]
$$


Here $\mu_{\mathrm{i}}$ is the permanent dipole moment of the isolated molecule.

$\alpha$ is the Polarizability involving both atomic and electronic deformation polarization.

$\mathrm{T}_{\mathrm{ik}} \mathrm{m}_{\mathrm{k}}$ is the tensor product representing the first approximation of the field created by $\mathrm{k}^{\text {th }}$ molecule in the region of the $i^{\text {th }}$ molecule.

Since orientation effects and deformation effects could not be separated, a mean effective internal field is defined.

Hence,

$$
\begin{aligned}
& \mathrm{F}=\mathrm{E}_{\mathrm{o}}-\sum_{\mathrm{k} \neq 1}\left\langle\left(\mathrm{~T}_{\mathrm{ik}} \cdot \mathrm{m}_{\mathrm{k}}\right) \mathrm{E}\right\rangle \\
& \left\langle\mathrm{M}_{\mathrm{E}}\right\rangle=\sum_{\mathrm{i}}\left(\left\langle\mu_{\mathrm{i}}\right)_{\mathrm{E}}\right\rangle+\alpha \mathrm{F}_{\mathrm{i}}
\end{aligned}
$$

According to Kirkwood, dispersion forces are practically independent of $E_{0}$. The total potential energy $U$ consists of two parts.

$$
\mathrm{U}\left(\mathrm{X}, \mathrm{E}_{0}\right)=\mathrm{U}_{1}(\mathrm{X})+\mathrm{U}_{2}\left(\mathrm{X}, \mathrm{E}_{0}\right)
$$

Here $U_{1}$ is due to dispersion forces and $U_{2}$ is due to electrostatic interaction of the dipoles with external field.

$$
\mathrm{U}_{2}\left(\mathrm{X}, \mathrm{E}_{0}\right)=-\sum \mathrm{p}_{\mathrm{i}} \mathrm{E}_{0}
$$

$\mathrm{P}$ is the internal moment of a set of non-formable molecules in the cavity.

If $\theta_{\mathrm{ij}}$ represents the angle between the

orientation of $i^{\text {th }}$ and $\mathrm{j}^{\text {th }}$ dipole, we can write

$$
\left\langle\mu_{\mathrm{i}} \mathrm{P}_{\mathrm{i}}\right\rangle=\frac{\mu^{2} \sum_{\mathrm{j}=1} \int \cos \theta_{\mathrm{ij}} \exp \left(-\mathrm{U}_{2} / \mathrm{KT}\right) \mathrm{dx}}{\int \exp \left(-\mathrm{U}_{2} / \mathrm{KT}\right) \mathrm{dx}}
$$

Here $\mu$ is the dipole moment of the representative molecule in the gaseous state. Defining ' $g$ 'as

$$
g=\sum_{j=1}\left\langle\cos \theta_{i j}\right\rangle=\frac{1}{\mu^{2}} \int W\left(X_{i}\right) \mu_{i} P_{i} d x
$$

where $\mathrm{W}\left(\mathrm{X}_{\mathrm{i}}\right)$ is the statistical weight factor of the $i^{\text {th }}$ molecule Now,

$$
\left\langle\cos \theta_{\mathrm{ij}}\right\rangle=\frac{\int \cos \theta_{\mathrm{ij}} \exp \left(-\mathrm{U}_{2} / \mathrm{KT}\right) \mathrm{dx}_{\mathrm{i}} \mathrm{dx}_{\mathrm{j}}}{\int \exp \left(-\mathrm{U}_{2} / \mathrm{KT}\right) \mathrm{dx}_{\mathrm{i}} \mathrm{dx}_{\mathrm{j}}}
$$

Here $\mathrm{U}_{2}$ is the rotational intermolecular interaction energy of the molecules, $\mathrm{dX}_{\mathrm{i}}, \mathrm{dX} \mathrm{j}_{\mathrm{j}}$ are co-ordinates to represent $\mathrm{i}^{\mathrm{th}}$ and $\mathrm{j}^{\text {th }}$ molecules.

$$
\begin{aligned}
& \frac{(\varepsilon-1)(2 \varepsilon+1)}{3 \varepsilon}=\frac{4 \pi \mathrm{N}_{\mathrm{A}}}{3 \mathrm{KT}} \mathrm{W}\left(\mathrm{X}_{\mathrm{i}}\right) \mu_{\mathrm{i}} \mathrm{P}_{\mathrm{i}} \mathrm{dx} \\
& \frac{(\varepsilon-1)(2 \varepsilon+1)}{3 \varepsilon}=\frac{4 \pi \mathrm{N}_{\mathrm{A}}}{3 \mathrm{KT}} \mathrm{g} \mu^{2}
\end{aligned}
$$

Taking into account the deformation polarization, electronic as well as atomic

$$
\frac{(\varepsilon-1)(2 \varepsilon+1)}{3 \varepsilon}=\frac{4 \pi \mathrm{N}_{\mathrm{A}} g \mu^{2}}{3 \mathrm{KTV}}+\frac{4 \pi \mathrm{N}_{\mathrm{A}} \alpha}{3 \mathrm{~V}}
$$

A model in which no boundary effect needs to be considered has been given by Frohlich [1]. He was able to replace the molecules by a set of non-deformable point dipoles of moment $\mathrm{P}$, placed in continuous medium of dielectric constant $\varepsilon$. By treating the deformation polarization as a macroscopic phenomenon, he was able to show that this takes care of deformation effects. The moment of the spherical molecule is then

$$
\begin{aligned}
& \mathbf{P}=\left[\frac{\varepsilon_{\infty}+\boldsymbol{\alpha}}{3} \mu\right] \\
& \frac{\left(\varepsilon-\varepsilon_{\infty}\right)\left(2 \varepsilon+\varepsilon_{\infty}\right)}{3 \varepsilon}=\frac{4 \pi \mathrm{N}_{\mathrm{A}} \mathrm{d}}{3 \mathrm{KT} \mathrm{M}}\left\langle\mathrm{P}^{1} \mathrm{M}^{*}\right\rangle
\end{aligned}
$$

where $\mathrm{N}_{\mathrm{A}}$ - Avogadro's number

d - Density of the medium

M - Molecular weight

$M^{*}$ - Moment of the spherical cavity placed in a continuous dielectric medium with a moment defined by $\mathrm{P}^{\prime}$. Therefore,

$$
\left\langle\mathrm{P}^{1} \mathrm{M}^{*}\right\rangle=\frac{\mathrm{K} \mathrm{T} \mathrm{M}}{4 \pi \mathrm{N}_{\mathrm{A}} \mathrm{d}} \frac{\left(\varepsilon-\varepsilon_{\infty}\right)\left(2 \varepsilon+\varepsilon_{\infty}\right)}{3 \varepsilon}
$$

If the fundamental unit is the molecule itself, then

$$
\left\langle\mu \mathrm{M}^{*}\right\rangle=\mathrm{g} \mu^{2}=\frac{9 \mathrm{KTM}}{4 \pi \mathrm{N}_{\mathrm{A}} \mathrm{d}} \frac{\left(\varepsilon-\varepsilon_{\infty}\right)\left(2 \varepsilon+\varepsilon_{\infty}\right)}{\left(\varepsilon_{\infty}+2\right)^{2}}
$$

The dimensionless parameter ' $\mathrm{g}$ ' in this equation reflects the average mutual orientation correlation between the representative dipolar molecule and its neighbors. According to this equation, ' $g$ ' is always positive; the phenomenological generalization of Kirkwood formula as given above was further refined by many workers [2-4]. Though they were able to provide the necessary ingredients for a correct microscopic theory, the phenomenological expressions given by the equation (15) completely holds good for polarizable species [5]. It is obvious that ' $\mathrm{g}$ ' describes something about the orientation ordering of molecules in a liquid through the angular correlation of the neighboring dipoles and hence a measurement of ' $g$ ' could give useful information about the local structure of the liquid.

\section{B. DIPOLAR EXCESS THERMODYNAMIC FUNCTIONS}

Meaningful information concerning the cohesive energy of a system by employing different experimental techniques can be obtained from these measurements of thermodynamic excess functions and is found to be more significant since these functions have been utilized to interpret the solution models.

\section{THERMODYNAMIC EXCESS FUNCTION DUE TO DIPOLAR INTERACTIONS}

The energy of a polar molecule in a solution consists of

i) An interaction energy $(-\mu \mathrm{R})$ for a dipole in a field

ii) An interaction energy $\left(\frac{1}{2} \mu \mathrm{R}\right)$ resulting from polarization of the surrounding molecules and 
iii) An energy ( $\left.\frac{1}{2} \alpha R^{2}\right)$ arising from polarization of the surrounding molecules themselves.

Huskell [6] developed a thermodynamic model that treats explicitly the dipole-dipole and dipole - inducted dipole interactions based on Onsager's theory. For a binary mixture, it is possible to develop a suitable partition function and calculate Helmholtz free energy change on mixing due to the dipolar interactions based on Onsager's theory.

However the model does not include the effect of dispersion forces and the short-range correlations due to association. Winklemen and Quitsch [7] utilized the concept of correlation in the statistical theory of RamShaw [8], Wortheim's [9] mean spherical model and formulate a themodynamical equation for the calculation of the dipolar excess thermodynamic functions. This theory includes mutual correlation between like and unlike polar molecules. Davis and Douheret [10] used the four-segment composition model and estimated the dielectric properties of polar liquids. Tripathy and Swain [11], Ray and Roy [12] and Sabesan et al.[13] found that Winklemann and Quitzsch expression is the most appropriate one for the study of dipolar excess thermodynamic properties of associated liquids in an inert solvent in the study. We have attempted to calculate the dipolar excess free energy using our values of the linear correction factor ' $\mathrm{g}$ '. A survey of literature shows that no such studies have been done for the systems which we have taken. The excess Helmholtz free energy of mixing due to the dipolar interaction is given by

$$
\Delta \mathrm{F}^{\mathrm{E}}=\frac{-\mathrm{N}_{\mathrm{A}}}{2}\left[\left(\mathrm{R}_{\mathrm{f} 2}-\mathrm{R}_{\mathrm{f} 20}\right)\left(\mathrm{X}_{2} \mu_{2}^{2}\left(1+\mathrm{X}_{2}(\mathrm{~g}-1)\right)\right)\right]
$$

where

$$
\begin{aligned}
& \mathrm{R}_{\mathrm{f} 20}=\frac{8 \pi \mathrm{N}_{\mathrm{A}}}{9 \mathrm{~V}_{2}} \frac{\left(\varepsilon_{2}-1\right)\left(\varepsilon_{\infty}+2\right)}{\left(2 \varepsilon_{2}+\varepsilon_{\infty}\right)} \\
& \mathrm{R}_{\mathrm{f} 2}=\frac{8 \pi \mathrm{N}_{\mathrm{A}}}{9 \mathrm{~V}_{2}} \frac{(\varepsilon-1)\left(\varepsilon_{\infty}+2\right)}{\left(2 \varepsilon+\varepsilon_{\infty}\right)}
\end{aligned}
$$

The dipolar excess free energy of mixing is positive in the entire concentration range. It is found that at high dilution, the contributions due to long-range interactions are given by the value of $\Delta F_{0}^{E}$. The interaction arising due to short-range interactions is indicated by the value of $\Delta \mathrm{F}_{22}^{\mathrm{E}}$.

$$
\begin{aligned}
& \Delta \mathrm{F}_{0}^{\mathrm{E}}=\frac{-\mathrm{N}_{\mathrm{A}}}{2}\left[\left(\mathrm{R}_{\mathrm{f} 2}-\mathrm{R}_{\mathrm{f} 20}\right) \mathrm{X}_{2} \mu_{2}^{2}\right] \\
& \Delta \mathrm{F}_{22}^{\mathrm{E}}=\frac{-\mathrm{N}_{\mathrm{A}}}{2}\left[\left(\mathrm{R}_{\mathrm{f} 2}-\mathrm{R}_{\mathrm{f} 20}\right) \mathrm{X}_{2} \mu_{2}^{2}(\mathrm{~g}-1)\right] \\
& \Delta \mathrm{F}^{\mathrm{E}}=\Delta \mathrm{F}_{0}^{\mathrm{E}}+\Delta \mathrm{F}_{22}^{\mathrm{E}}
\end{aligned}
$$

\section{SCOPE OF THE PRESENT WORK}

The dielectric parameters such as Kirkwood correlation factor, effective correlation factor, corrective correlation factor and thermo dynamical excess parameters for a mixture of the following binary liquids were determined.

1. diethyl phthalate + isobutanol

2. diethyl phthalate + benzonitrile

Dielectric constant at a static frequency, refractive index corresponding to sodium D-line and density of the mixture at different concentrations were determined. The solution was prepared for different concentrations in terms of mole fraction. The experiment was carried out at the temperatures $303 \mathrm{~K}, 313 \mathrm{~K}$ and $323 \mathrm{~K}$.

\section{MATERIALS AND METHODS}

\section{Purification of Chemicals}

i) benzene

The BDH Analar variety of benzene was first treated with anhydrous calcium chloride, filtered and then dried over sodium. Then it was distilled. The liquid collected was redistilled after treating it with phosphorous pentoxide and collected at $80^{\circ} \mathrm{C}$.

\section{ii) diethyl phthalate, isobutanol and benzonitrile}

Aldrich quality of diethyl phthalate, isobutanol and benzonitrile obtained from Sisco Research Lab., Mumbai, were used without further purification

\section{A. DIELCTRIC CONSTANT MEASUREMENTS}

The dielectric constant was determined by the measurement of the capacity of a cylindrical cell (with and without liquid) at $1 \mathrm{KHZ}$ by a digital LCR meter (VLCR 7) supplied by Ms. Vasavi Electronics, Secunderabad. The temperature was maintained constant using thermostat supplied by Ms. Raagaa Industries, Chennai. The fluctuation in temperature was $\pm 0.05^{\circ} \mathrm{C}$. From the readings of VLCR, the dielectric constant was calculated using the calibrated data. The scale of the instrument was calibrated using standard liquids like carbon tetrachloride, benzene, toluene and chlorobenzene.

\section{B. DIPOLE MOMENT MEASUREMENTS}

\section{Halverstadt and Kumler method.}

Halverstadt and Kumler assumed linear variation of $\varepsilon$ and the specific volume $\mathrm{v}$ with concentration

$$
\begin{aligned}
& \varepsilon=\varepsilon_{1}+\alpha \mathrm{w}_{2} \\
& \mathrm{v}=\mathrm{v}_{1}+\beta \mathrm{w}_{2}
\end{aligned}
$$

This method was used to determine the dipole moment.

\section{INTRODUCTION OF EFFECTIVE CORRELATION FACTOR}


The Kirkwood correlation factor $g$ is also a parameter affording information regarding orientation of electric dipoles in polar liquids. The Kirkwood correlation factor $(\mathrm{g})$ for the pure liquid is given by the expression

$$
\frac{4 \pi \mathrm{N}_{\mathrm{A}} \mu^{2} \rho}{9 \mathrm{~K} \mathrm{~T} \mathrm{M}} \mathrm{g}=\frac{\left(\varepsilon_{0}-\varepsilon_{\infty}\right)\left(2 \varepsilon+\varepsilon_{\infty}\right)}{\varepsilon\left(\varepsilon_{\infty}+2\right)^{2}}
$$

where $\mu$ is the dipole moment in the gas phase. $\rho$ is the density at a temperature $\mathrm{T}, \mathrm{M}$ is the molecular weight, $\mathrm{K}$ is the Boltzmann constant and $\mathrm{N}_{\mathrm{A}}$ is the Avogadro number. For a mixture of two polar liquids say $\mathrm{A}$ and $\mathrm{B}$ the equation is modified by Kumbharkhane using some assumptions.

Assume that ( $\mathrm{g}$ ) for the mixture is expressed by an effective averaged correlation factor ( $g^{\text {eff }}$ ) such that Kirkwood equation for the mixture can be expressed as

$$
\begin{gathered}
\frac{4 \pi \mathrm{N}_{\mathrm{A}}}{9 \mathrm{~K} \mathrm{~T}}\left(\frac{{ }_{\mathrm{A}}^{2} \rho_{\mathrm{A}}}{\mathrm{M}_{\mathrm{A}}} \mathrm{X}_{\mathrm{A}}+\frac{\mu_{\mathrm{B}}^{2} \rho_{\mathrm{B}}}{\mathrm{M}_{\mathrm{B}}} \mathrm{X}_{\mathrm{B}}\right) \mathrm{g} \text { eff } \\
=\frac{\left(\varepsilon_{\mathrm{m}}-\varepsilon_{\infty \mathrm{m}}\right)\left(2 \varepsilon_{0 \mathrm{~m}}+\varepsilon_{\infty \mathrm{m}}\right)}{\varepsilon_{\mathrm{m}}\left(\varepsilon_{\infty \mathrm{m}}+2\right)^{2}}
\end{gathered}
$$

where $X_{A}$ and $X_{B}$ are the volume fractions of liquids $\mathrm{A}$ and $\mathrm{B}$ respectively and $\mathrm{g}^{\text {eff }}$ is the effective Kirkwood correlation factor for a binary mixture.

Another way to visualize the variation in Kirkwood correlation factor is to assume that the correlation factor for molecules A and B in mixture contribute to effective ' $\mathrm{g}$ ' in some extent by using various theories. In the absence of exact theory exploring these quantities, available theories with some assumptions can provide the trend regarding interactions and the structural changes.

\section{EXCESS PARAMETER}

Studying the excess dielectric properties can access the useful information regarding the structural changes in binary mixtures. Let $\mathrm{A}$ and $\mathrm{B}$ be two molecular systems with measurable macroscopic properties $\mathrm{P}_{\mathrm{A}}$ and $\mathrm{P}_{\mathrm{B}}$. If we prepare the mixture of $\mathrm{A}$ and $\mathrm{B}$ having mole fractions $\mathrm{X}_{\mathrm{A}}$ and $\mathrm{X}_{\mathrm{B}}=1-\mathrm{X}_{\mathrm{A}}$, the excess macroscopic property $\mathrm{P}^{\mathrm{E}}$ corresponding to mixture is defined as

$$
\mathrm{P}^{\mathrm{E}}=\mathrm{P}_{\mathrm{AB}}-\left(\mathrm{P}_{\mathrm{A}} \mathrm{X}_{\mathrm{A}}+\mathrm{P}_{\mathrm{B}} \mathrm{X}_{\mathrm{B}}\right)
$$

where $\mathrm{P}_{\mathrm{AB}}$ is the measured value of property $\mathrm{P}$ for mixture. The value of $\mathrm{P}^{\mathrm{E}}$ provides information regarding interaction between $\mathrm{A}$ and $\mathrm{B}$. $\mathrm{P}^{\mathrm{E}}>0$ indicates that interaction between

$\mathrm{A}$ and $\mathrm{B}$ leads to increase in the value of property $\mathrm{P}$.

Similarly, $\mathrm{P}^{\mathrm{E}}<0$ indicates decrease in macroscopic property $\mathrm{P}$. In the present work, excess dielectric properties are determined corresponding to static permittivity and molar volume. The excess permittivity ( $\varepsilon^{\mathrm{E}}$ ) is defined as

$$
\varepsilon^{\mathrm{E}}=\left(\varepsilon-\varepsilon_{\infty}\right)_{\mathrm{m}}-\left[\left(\varepsilon-\varepsilon_{\infty}\right)_{\mathrm{A}} \mathrm{X}_{\mathrm{A}}+\left(\varepsilon-\varepsilon_{\infty}\right)_{\mathrm{B}} \mathrm{X}_{\mathrm{B}}\right]
$$

proportion to their pure liquid values $\mathrm{g}_{\underline{\mathrm{A}}}$ and $\mathrm{g}_{\underline{B}}$. Under this assumption Kirkwood equation for the mixture can be written as

$$
\begin{gathered}
\frac{4 \pi N_{A}}{9 K T}\left(\frac{\mu_{A}^{2} \rho_{A} g_{A}}{M_{A}} X_{A}+\frac{\mu_{B}^{2} \rho_{B} g_{B}}{M_{B}} X_{B}\right) g_{f} \\
=\frac{\left(\varepsilon_{m}-\varepsilon_{\infty m}\right)\left(2 \varepsilon_{0 m}+\varepsilon_{\infty m}\right)}{\varepsilon_{m}\left(\varepsilon_{\infty m}+2\right)^{2}}
\end{gathered}
$$

where $g_{f}$ is the correlation factor for mixture. The value of $g^{\text {eff }}$ in equation will change from $g_{A}$ to $g_{B}$ as the fraction of component $\mathrm{B}$ increases from zero to unity. In equation (26), $\mathrm{g}_{\mathrm{f}}$ is unity for pure liquids and will remain close to unity if there is no interaction between A and B.

\section{DIELECTRIC PARAMETER RELATED TO MOLECULAR BEHAVIORS}

There are different formulae with which one can correlate dielectric parameters with molecular activities in liquid. The correlation between dielectric parameters and molecular interaction as well as the structural changes in mixture can be explored

to

where $\mathrm{X}$ is the mole fraction and the subscripts $\mathrm{m}$, $\mathrm{A}$ and $\mathrm{B}$ represent mixture, solvent and solute respectively. The excess permittivity $\varepsilon^{E}$ may provide qualitative information about the multimer formation in mixtures as follows.

1. $\varepsilon^{\mathrm{E}}=0$ indicates that the liquid $\mathrm{A}$ and $\mathrm{B}$ do not interact at all.

2. $\varepsilon^{\mathrm{E}}<0$ indicates that the liquid $\mathrm{A}$ and $\mathrm{B}$ interact in such a way that the total effective dipole gets reduced. The liquids $\mathrm{A}$ and $\mathrm{B}$ may form multimers leading to the less effective dipoles. In general, the negative excess permittivity indicates the formation of multimers in the binary mixtures.

3. $\varepsilon^{\mathrm{E}}>0$ indicates that the liquids $\mathrm{A}$ and $\mathrm{B}$ interact in such a way that the total effective dipole moment increases. There is a tendency to form multimers, dipoles aligned in parallel direction.

The excess molar volume may be defined as

$\mathrm{V}^{\mathrm{E}}=\mathrm{V}_{\mathrm{m}}-\left(\mathrm{V}_{\mathrm{A}} \mathrm{X}_{\mathrm{A}}+\mathrm{V}_{\mathrm{B}} \mathrm{X}_{\mathrm{B}}\right)$

If $\mathrm{V}^{\mathrm{E}}$ is positive then it refers to the breaking of $\mathrm{H}$ bonds and hence demolition of multimers. Negative values of $\mathrm{V}^{\mathrm{E}}$ refer to the association due to dipoledipole interaction. 
Diethyl Phthalate + Isobutanol

Table 1. Variation of $\mathrm{g}^{\text {eff }}, \mathrm{g}_{\mathrm{f}}, \varepsilon^{\mathrm{E}}$ and $\mathrm{f}_{\mathrm{B}}$ with $\mathrm{X}_{2}$

\begin{tabular}{|c|c|c|c|c|c|c|c|}
\hline $\begin{array}{r}\text { Temp } \\
\text { K }\end{array}$ & $\mathrm{X}_{2}$ & $\mathrm{E}$ & $\varepsilon_{\alpha}$ & $\mathrm{g}^{\text {eff }}$ & $\mathrm{g}_{\mathrm{f}}$ & $\varepsilon^{\mathrm{E}}$ & $f_{B}$ \\
\hline \multirow{11}{*}{303} & 0.0 & 3.3599 & 2.2103 & 0.2209 & 1.00 & 0.000 & 1.0000 \\
\hline & 0.1 & 3.3914 & 2.1978 & 0.2357 & 0.81 & -0.288 & 0.9866 \\
\hline & 0.2 & 3.4904 & 2.1883 & 0.2630 & 0.72 & -0.512 & 0.9450 \\
\hline & 0.3 & 3.5544 & 3.0450 & 0.0792 & 0.68 & -0.842 & 0.9187 \\
\hline & 0.4 & 3.7002 & 2.1500 & 0.3308 & 0.63 & -0.928 & 0.8600 \\
\hline & 0.5 & 3.7988 & 2.1167 & 0.3718 & 0.61 & -1.128 & 0.8214 \\
\hline & 0.6 & 4.1488 & 2.1103 & 0.4564 & 0.65 & -1.104 & 0.6903 \\
\hline & 0.7 & 4.5133 & 2.0664 & 0.5651 & 0.70 & -1.027 & 0.5626 \\
\hline & 0.8 & 5.0822 & 2.0372 & 0.7187 & 0.79 & -0.761 & 0.3778 \\
\hline & 0.9 & 5.8475 & 1.9592 & 0.9581 & 0.94 & -0.250 & 0.1514 \\
\hline & 1.0 & 6.4013 & 1.9307 & 1.1384 & 1.00 & 0.000 & 0.0000 \\
\hline \multirow{11}{*}{313} & 0.0 & 3.2912 & 2.2037 & 0.2175 & 0.99 & 0.000 & 1.0000 \\
\hline & 0.1 & 3.3519 & 2.2115 & 0.2322 & 0.80 & -0.281 & 0.9740 \\
\hline & 0.2 & 3.4212 & 2.1833 & 0.2600 & 0.71 & -0.517 & 0.9448 \\
\hline & 0.3 & 3.5282 & 2.1618 & 0.2950 & 0.66 & -0.722 & 0.9007 \\
\hline & 0.4 & 3.6324 & 2.1544 & 0.3267 & 0.62 & -0.944 & 0.8587 \\
\hline & 0.5 & 4.0222 & 2.1179 & 0.4293 & 0.70 & -0.851 & 0.7098 \\
\hline & 0.6 & 4.3385 & 2.0929 & 0.5184 & 0.73 & -0.843 & 0.5969 \\
\hline & 0.7 & 4.7890 & 2.0486 & 0.6515 & 0.81 & -0.682 & 0.4464 \\
\hline & 0.8 & 4.7890 & 2.0244 & 0.6845 & 0.75 & -0.991 & 0.4464 \\
\hline & 0.9 & 5.5360 & 1.9530 & 0.9218 & 0.90 & -0.506 & 0.2182 \\
\hline & 1.0 & 6.3225 & 1.8994 & 1.1816 & 1.04 & 0.000 & 0.0000 \\
\hline \multirow{11}{*}{323} & 0.0 & 3.3178 & 2.1913 & 0.2330 & 1.06 & 0.000 & 1.0000 \\
\hline & 0.1 & 3.3719 & 2.1889 & 0.2502 & 0.86 & -0.258 & 0.9757 \\
\hline & 0.2 & 3.4474 & 2.1686 & 0.2782 & 0.76 & -0.476 & 0.9423 \\
\hline & 0.3 & 3.5150 & 2.1600 & 0.3023 & 0.68 & -0.714 & 0.9129 \\
\hline & 0.4 & 3.6002 & 2.1296 & 0.3392 & 0.64 & -0.912 & 0.8765 \\
\hline & 0.5 & 3.7601 & 2.1127 & 0.3896 & 0.63 & -1.049 & 0.8100 \\
\hline & 0.6 & 3.9806 & 2.0860 & 0.4604 & 0.65 & -1.116 & 0.7217 \\
\hline & 0.7 & 4.2661 & 2.0435 & 0.5582 & 0.69 & -1.102 & 0.6129 \\
\hline & 0.8 & 4.7331 & 2.0173 & 0.6974 & 0.77 & -0.923 & 0.4461 \\
\hline & 0.9 & 5.5389 & 1.9480 & 0.9554 & 0.94 & -0.362 & 0.1845 \\
\hline & 1.0 & 6.1610 & 1.8939 & 1.1833 & 1.04 & 0.000 & 0.0000 \\
\hline
\end{tabular}


Table 2. Variation of Thermo dynamic excess free energies with $\mathrm{X}_{2}$

\begin{tabular}{|c|c|c|c|c|c|}
\hline $\begin{array}{c}\text { Temp } \\
\mathrm{K} \\
\end{array}$ & $X_{2}$ & $\begin{array}{c}\Delta \mathrm{F}_{0}^{\mathrm{E}} \\
\mathrm{J} / \text { mole } \\
\end{array}$ & $\begin{array}{c}\Delta \mathrm{F}_{22}^{\mathrm{E}} \\
\mathrm{J} / \text { mole } \\
\end{array}$ & $\begin{array}{c}\Delta \mathrm{F}_{12}^{\mathrm{E}} \\
\mathrm{J} / \text { mole }\end{array}$ & $\begin{array}{l}\Delta \mathrm{F}^{\mathrm{E}} \\
\quad \mathrm{J} / \text { mole } \\
\end{array}$ \\
\hline \multirow{9}{*}{303} & 0.1 & 7757 & 1210 & 557 & 9524 \\
\hline & 0.2 & 5720 & 1631 & 414 & 7765 \\
\hline & 0.3 & 4810 & 2137 & 188 & 7135 \\
\hline & 0.4 & 3652 & 2367 & -131 & 5888 \\
\hline & 0.5 & 2851 & 2497 & 380 & 5728 \\
\hline & 0.6 & 1372 & 2135 & 301 & 3808 \\
\hline & 0.7 & 245 & 1663 & 62 & 1971 \\
\hline & 0.8 & 589 & 1044 & -486 & 1147 \\
\hline & 0.9 & 457 & 373 & -263 & 567 \\
\hline \multirow{9}{*}{313} & 0.1 & 6712 & 1626 & 3076 & 11414 \\
\hline & 0.2 & 5712 & 2871 & 2319 & 10902 \\
\hline & 0.3 & 4630 & 3703 & 1914 & 10246 \\
\hline & 0.4 & 3653 & 4186 & 1137 & 8977 \\
\hline & 0.5 & 1750 & 3651 & 1237 & 6637 \\
\hline & 0.6 & 549 & 3077 & 608 & 4234 \\
\hline & 0.7 & -532 & 2233 & -53 & 1648 \\
\hline & 0.8 & -452 & 2225 & -436 & 1337 \\
\hline & 0.9 & -330 & 1755 & -644 & 881 \\
\hline \multirow{9}{*}{323} & 0.1 & 5174 & 2216 & 4925 & 12315 \\
\hline & 0.2 & 4098 & 2469 & 4980 & 11547 \\
\hline & 0.3 & 3235 & 2899 & 4765 & 10899 \\
\hline & 0.4 & 2322 & 3247 & 852 & 6421 \\
\hline & 0.5 & 1986 & 3688 & 1595 & 7269 \\
\hline & 0.6 & 1185 & 4109 & -401 & 4893 \\
\hline & 0.7 & 956 & 4587 & -2856 & 2687 \\
\hline & 0.8 & 766 & 5321 & -4359 & 1728 \\
\hline & 0.9 & 433 & 5912 & -5372 & 973 \\
\hline
\end{tabular}


Diethyl Phthalate + Benzonitrile

Table 3. Variation of $g^{\text {eff }}, g_{f}, \varepsilon^{E}$ and $f_{B}$ with $X_{2}$

\begin{tabular}{|c|c|c|c|c|c|c|c|}
\hline $\begin{array}{ll}\text { Temp } & \\
& \mathrm{K}\end{array}$ & $\mathrm{X}_{2}$ & E & $\varepsilon_{\alpha}$ & $\mathrm{g}^{\text {eff }}$ & $g_{f}$ & $\varepsilon^{\mathrm{E}}$ & $\mathrm{f}_{\mathrm{B}}$ \\
\hline \multirow{11}{*}{303} & 0.0 & 6.9601 & 2.2127 & 0.7946 & 1.0000 & 0.000 & 1.0000 \\
\hline & 0.1 & 7.98924 & 2.2222 & 0.7064 & 0.9323 & -0.531 & 0.8920 \\
\hline & 0.2 & 9.72897 & 2.2240 & 0.7178 & 0.9755 & -0.345 & 0.7354 \\
\hline & 0.3 & 10.3744 & 2.2293 & 0.6429 & 0.8914 & -1.255 & 0.6835 \\
\hline & 0.4 & 11.2788 & 2.2353 & 0.6050 & 0.8513 & -1.908 & 0.6153 \\
\hline & 0.5 & 12.1371 & 2.2386 & 0.5746 & 0.8175 & -2.604 & 0.5547 \\
\hline & 0.6 & 14.8359 & 2.2461 & 0.6373 & 0.9146 & -1.464 & 0.3842 \\
\hline & 0.7 & 16.5261 & 2.2539 & 0.6431 & 0.9293 & -1.333 & 0.2893 \\
\hline & 0.8 & 18.7753 & 2.2623 & 0.6685 & 0.9717 & -0.643 & 0.1735 \\
\hline & 0.9 & 20.8852 & 2.2717 & 0.6838 & 0.9987 & -0.093 & 0.0735 \\
\hline & 1.0 & 22.5370 & 2.2792 & 0.6819 & 1.0000 & 0.000 & 0.0000 \\
\hline \multirow{11}{*}{313} & 0.0 & 6.2269 & 2.2097 & 0.7066 & 1.0000 & 0.000 & 1.0000 \\
\hline & 0.1 & 7.3297 & 2.2121 & 0.6575 & 0.9465 & -0.358 & 0.8755 \\
\hline & 0.2 & 8.5116 & 2.2144 & 0.6338 & 0.9220 & -0.636 & 0.7599 \\
\hline & 0.3 & 8.92327 & 2.2195 & 0.5575 & 0.8166 & -1.688 & 0.7230 \\
\hline & 0.4 & 9.8741 & 2.2204 & 0.5392 & 0.7937 & -2.196 & 0.6431 \\
\hline & 0.5 & 10.2155 & 2.2276 & 0.4889 & 0.7225 & -3.320 & 0.6160 \\
\hline & 0.6 & 12.4761 & 2.2204 & 0.5495 & 0.8144 & -2.510 & 0.4533 \\
\hline & 0.7 & 14.9185 & 2.2195 & 0.6042 & 0.8976 & -1.525 & 0.3019 \\
\hline & 0.8 & 17.1413 & 2.2144 & 0.6411 & 0.9542 & -0.756 & 0.1794 \\
\hline & 0.9 & 18.7418 & 2.2121 & 0.6480 & 0.9660 & -0.611 & 0.0982 \\
\hline & 1.0 & 20.8084 & 2.2097 & 0.6699 & 1.0000 & 0.000 & 0.0000 \\
\hline \multirow{11}{*}{323} & 0.0 & 5.5557 & 2.1996 & 0.6228 & 1.0009 & 0.000 & 1.0000 \\
\hline & 0.1 & 6.6273 & 2.2014 & 0.5975 & 0.9877 & -0.157 & 0.8610 \\
\hline & 0.2 & 7.4071 & 2.2058 & 0.5515 & 0.9273 & -0.609 & 0.7723 \\
\hline & 0.3 & 8.1001 & 2.2088 & 0.5136 & 0.8737 & -1.146 & 0.7001 \\
\hline & 0.4 & 8.4284 & 2.2127 & 0.4612 & 0.7911 & -2.048 & 0.6677 \\
\hline & 0.5 & 8.6967 & 2.2219 & 0.4170 & 0.7198 & -3.016 & 0.6421 \\
\hline & 0.6 & 10.4125 & 2.2255 & 0.4590 & 0.7963 & -2.531 & 0.4919 \\
\hline & 0.7 & 13.6400 & 2.2389 & 0.5587 & 0.9729 & -0.544 & 0.2557 \\
\hline & 0.8 & 15.7532 & 2.2428 & 0.5945 & 1.0387 & 0.339 & 0.1228 \\
\hline & 0.9 & 17.6002 & 2.2485 & 0.6132 & 1.0743 & 0.953 & 0.0164 \\
\hline & 1.0 & 17.8974 & 2.2720 & 0.5695 & 1.0000 & 0.000 & 0.0000 \\
\hline
\end{tabular}


Table 4. Variation of Thermo dynamic excess free energies with $\mathrm{X}_{2}$

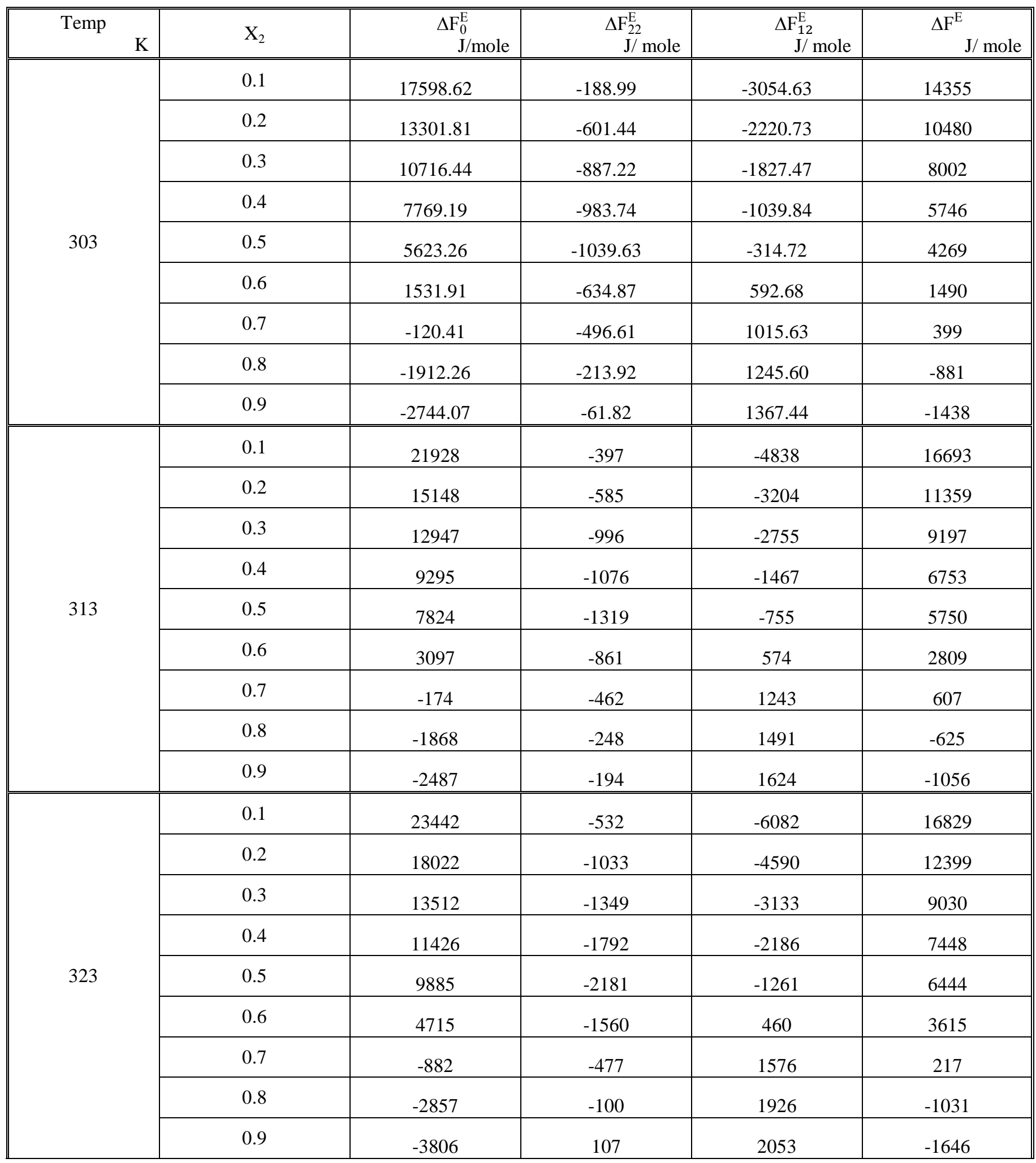


Diethyl Phthalate + Isobutanol

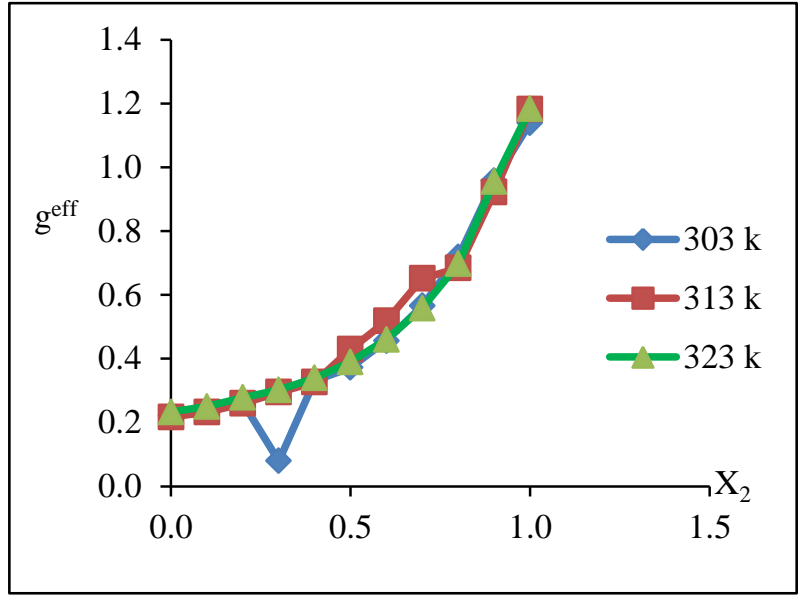

Fig. 1 - Variation of $g^{\text {eff }}$ with $X_{2}$

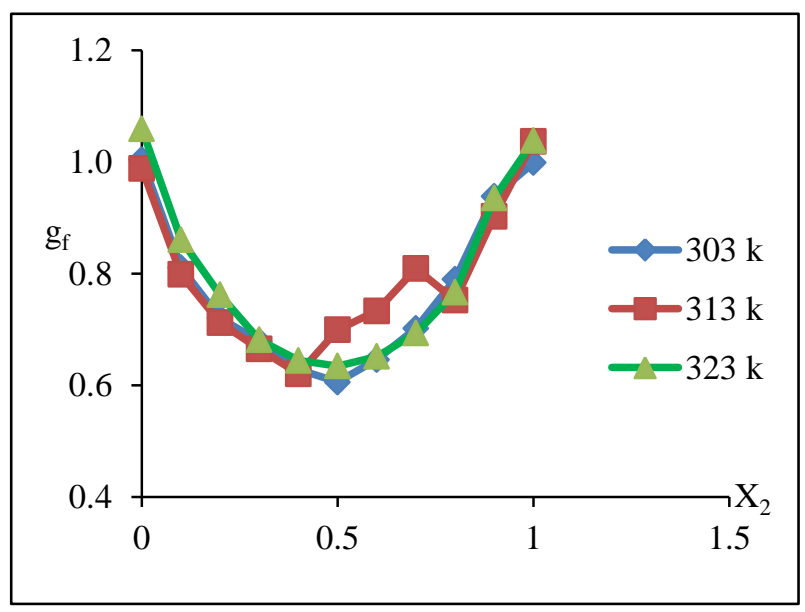

Fig. 2 - Variation of $g_{f}$ with $X_{2}$

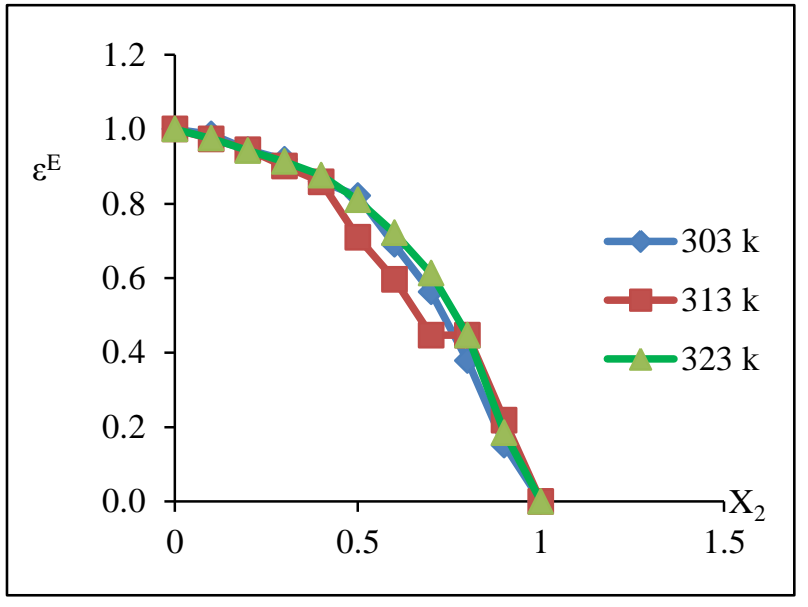

Fig. 3 - Variation of $\varepsilon^{E}$ with $X_{2}$



Fig. 4 - Variation of $f_{B}$ with $X_{2}$ 
Diethyl Phthalate + Benzonitrile

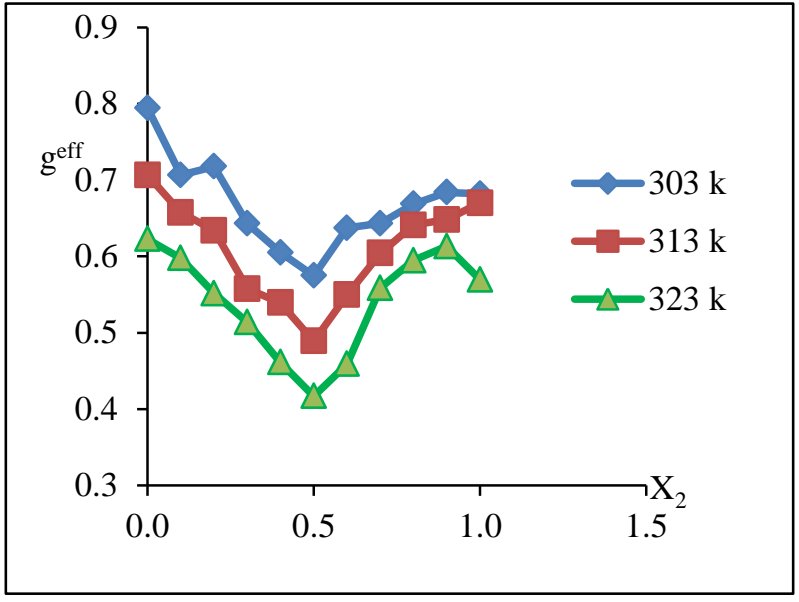

Fig. 5 - Variation of $g^{\text {eff }}$ with $X_{2}$

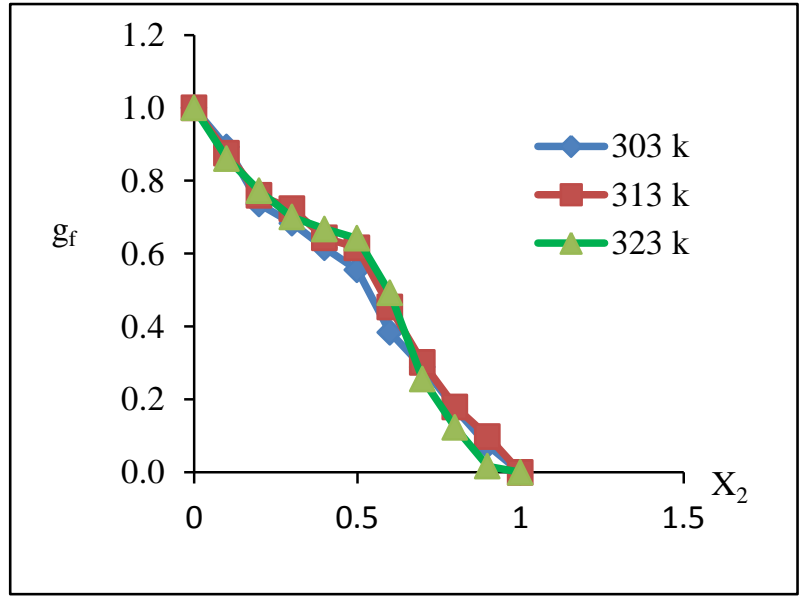

Fig. 6 - Variation of $g_{f}$ with $X_{2}$

\section{RESULTS}

The values of dielectric constants

$\left(\varepsilon_{0}\right.$ and $\left.\varepsilon_{\infty}\right)$, density $(\rho)$, the average effective correlation factor $\left(\mathrm{g}^{\text {eff }}\right)$ and the excess permittivity $\left(\varepsilon^{\mathrm{E}}\right)$ and the thermodynamic excess free energies

$\left(\Delta \mathrm{F}_{0}^{\mathrm{E}}, \Delta \mathrm{F}_{22}^{\mathrm{E}}\right.$,

$\Delta \mathrm{F}_{12}^{\mathrm{E}}$ and $\left.\Delta \mathrm{F}^{\mathrm{E}}\right)$ at different concentrations $\left(\mathrm{X}_{2}\right)$ of isobutanol and benzonitrile with diethyl phthalate at $303 \mathrm{~K}$, $313 \mathrm{~K}$ and $323 \mathrm{~K}$ are given in Tables 1 to 4 The variation of $\mathrm{g}^{\text {eff }}, \mathrm{g}, \varepsilon^{\mathrm{E}}$ and $\mathrm{f}_{\mathrm{B}}$ are graphically represented in Figs. 1 to 8

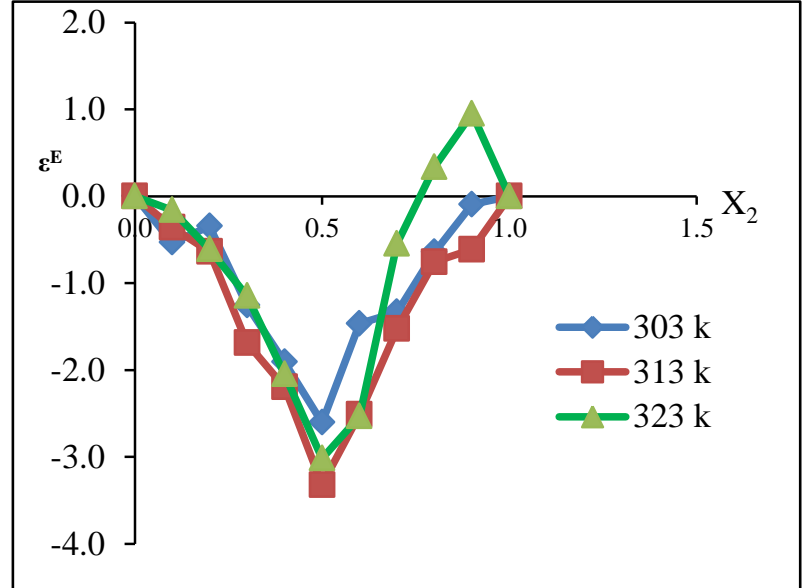

Fig. 7 - Variation of $\varepsilon^{E}$ with $X_{2}$



Fig. 8 - Variation of $f_{B}$ with $X_{2}$

\section{CONCLUSION}

From the Tables, it is found that values of $\varepsilon_{0}$ have a nonlinear variation with the concentration for all the systems studied. The non-linear variation of $\varepsilon_{0}$ confirms the presence of the interaction between the unlike molecules. Similar results were reported by Kroeger [14]. Vyas et al. [15] have pointed out that a non-linear variation of dielectric constant with concentration may be due to interaction between the molecules.

For the system diethyl phthalate + isobutanol, as the concentration increases, $\mathrm{g}^{\text {eff }}$ increases indicating that more 
parallel orientation is favoured. Similar results were reported by Helembi et al. [16]. This shows that addition of isobutanol makes the alignment of the dipoles more parallel. This may be due to the interaction between the unlike molecules. The interaction between the unlike molecules produces an electric field which makes dipoles to have more parallel orientation. The same trend happens at all temperatures.

For the system, diethyl phthalate + benzonitrile, $\mathrm{g}^{\text {eff }}$ exhibits a steady decreasing tendency as the concentration of nitrile goes on increasing. It favours the anti parallel orientation of the dipoles. This happens when $\mathrm{X}_{\mathrm{B}}$ is about $50 \%$. After this, $\mathrm{g}^{\text {eff }}$ increases indicating that more parallel orientation is favoured. Initially anti parallel orientation is favoured. When the concentration is more than $50 \%$, the molecular dipole orientation is changed from anti parallel to parallel.

Deviation of $g_{f}$ from unity indicates the interaction between the components in the mixture. For an ideal non interacting mixture $g_{f}$ must be unity and the magnitude of the deviation of $g_{f}$ from unity indicates the magnitude of interaction between the compounds. A greater deviation from unity means a larger strength of interaction [17].

For the system diethyl phthalate + isobutanol, the strength of the interaction between the unlike molecules is maximum when $\mathrm{X}_{\mathrm{B}}$ is about $50 \%$. The values of $\mathrm{g}_{\mathrm{f}}$ deviate more from unity indicating strong heterogeneous intermolecular interactions, as reported by $S$. Kumar [18]. The values of $g_{f}$ are found to depend more on concentration than temperature, as reported by Balamurugan. [19].

For the system diethyl phthalate + benzonitrile, the strength of the interaction between unlike molecules is maximum when $\mathrm{X}_{\mathrm{B}}$ is about $50 \%$. In nitrile rich region the deviation of $g_{f}$ from unity is small compared to phthalate rich region, indicating a weak hetero interaction. The same trend repeats at all temperatures. .

The excess permittivity is a dielectric parameter which provides valuable information regarding the interaction between the unlike molecules of the polar-polar liquid mixtures. The change in the value of $\varepsilon^{\mathrm{E}}$ with concentration is due to the interaction between dissimilar molecules, which may produce structural changes. For all the systems, it is found to vary with $X_{B}$.

For the system diethyl phthalate + isobutanol, the excess permittivity values are negative over the entire range of solute mole fractions at all temperatures studied. The negative value of $\varepsilon^{\mathrm{E}}$ indicates that the molecules in the mixture form multimers through H-bonding in such a way that the effective dipole moment gets reduced. Our results are in good agreement with those reported by Mehrotra. [20].
For the system diethyl phthalate + benzonitrile, the excess permittivity values are negative over the entire range of solute mole fractions at all temperatures studied. The negative value of $\varepsilon^{\mathrm{E}}$ indicates that the molecules in the mixture form multimers through $\mathrm{H}$-bonding in such a way that the effective dipole moment gets reduced.

It is found that the value of excess permittivity is large for benzonitrile with diethyl phthalate than alcohol with diethyl phthalate. Thus the interaction is stronger for the mixtures containing nitriles and the interaction is weaker for the mixtures containing alcohols [21].

The hetero interaction and homo interaction between the components of a liquid mixture can be studied by the determination of excess free energy on mixing. Values of excess free energy $\left(\Delta \mathrm{F}_{0}^{\mathrm{E}}\right)$ explains the long-range dipoledipole interaction between the molecules. The short-range interaction due to hydrogen bonding between the solute molecules is reflected by $\Delta \mathrm{F}_{\mathrm{jj}}^{\mathrm{E}}$ values. Values of $\Delta \mathrm{F}_{0}^{\mathrm{E}}$ suggest the presence of long-range dipole-dipole interaction. The increasing rate of $\Delta \mathrm{F}_{0}^{\mathrm{E}}$ with $\mathrm{X}_{2}$ indicates that the strength on the interaction also increases. This may probably be due to the increasing number of molecules of one component with its increasing concentration. For the systems studied, values of $\Delta \mathrm{F}_{0}^{\mathrm{E}}$ increase with concentration indicating the increase in the strength of the interaction [22].

For the system diethyl phthalate + isobutanol, value of $\Delta \mathrm{F}^{\mathrm{E}}{ }_{\mathrm{jj}}$ is positive and increases with concentration and is maximum when $\mathrm{X}_{\mathrm{B}}$ is about $50 \%$. This shows the breakage of $\mathrm{H}$ bonding [23]. After this, $\Delta \mathrm{F}_{\mathrm{jj}}^{\mathrm{E}}$ decreases. This shows the formation of H-bonding. When the temperature is increased, the shift of breaking of H-bonding into formation of $\mathrm{H}$ bonding takes place at lower concentrations. Conclusion on similar lines has been reported by Thenappan. [24].

For the system diethyl phthalate + benzonitrile, value of $\Delta \mathrm{F}^{\mathrm{E}}{ }_{\mathrm{jj}}$ is negative and increases with concentration and is maximum when $\mathrm{X}_{\mathrm{B}}$ is about $50 \%$. This shows the breakage of H-bonding. After this, $\Delta \mathrm{F}_{\mathrm{jj}}^{\mathrm{E}}$ decreases. This shows the formation of H-bonding. When the temperature is increased, the shift of breaking of $\mathrm{H}$-bonding into formation of $\mathrm{H}$ bonding takes place at lower concentrations.

The other dielectric parameter determined in the present study is Bruggeman parameter $\left(\mathrm{f}_{\mathrm{B}}\right)$, which gives information on the interaction between the components in the mixture. For the systems studied the values are found to vary non linearly with volume fraction at all temperatures as shown in the figures, which indicates that there is an interaction between the components [25]. 


\section{REFERENCES}

[1]H.Frohlich, 'Theory of Dielectrics', Clarendon Press, Oxford, 1958

[2]J.S. Hoye, G.Stell, Dielectric constant in terms of atom-atom correlation functions, J .Chem. Phys.,65, 18, 1976.

[3]J.D. Ramshaw, Existence of the dielectric constant in rigid-dipole fluids: The functional-derivative approach. J. Chem.Phys. 66, 3134, 1977

[4]M.S.Werthim, Theory of polar fluids. II J. Mol. Phy., 33,95,1977.

[5]P. Bordewijk, On the separation of long- range and short-range dipole correlations in polar fluids J. Chem. Phys., 33,1978.1

[6]R.W.Hasekell, Thermodynamic model of dipole-dipole and dipole-induced dipole interactions in polar mixtures, J. Phys. Chem., 73, 2916,1969.

[7]J. Winklemann, K.Quitzsch, Dielectric properties, binary liquid mixtures with, dimethylformamide J. Phys. Chem.,257, 45, 1976.

[8]Ramshaw, J. D.: Existence of the Dielectric Constant in Rigid Dipole Fluids, J. Chem. Phys. 57, 2684-2690 (1972).

[9]M.S.Werthim, Theory of polar fluids. I J. Mol. Phy., 26, 1425,1973.

[10]M.I. Davis, G.Douheret, Studies of dielectric properties of some binary hydroorganic systems,Thermo. Chemica Acta.,104 ,203,1986.

[11]S.Tripathy, B.B.Swain, Dielectric- properties of binary mixtures of some amines in nonpolar solvents-linear correlation factor, excess molar polarization, and excess Gibbs energy,Chem., Papers, 45, 321,1991.

[12]S.K. Ray, G.S.Roy, Dielectric Studies of Binary Mixtures of Polar Liquids: An Experimental Assessment of Applicability of Winkelmann-Quitzsch and Davis-Douheret Equations ,Proc.Indian Nati. Sci. Acd., 59, 205, 1993.

[13]R.Sabesan, V. Thiagarajan, S.Srinivasan,Studies of linear correlation factor of dielectric polarization and dipolar excess thermodynamic functions, Acta. Chim.Hungarica, 127,149, 1990 .

[14]M.K. Kroeger, Clustering and dielectric behavior of alcohols, J. Mol. Liqs.,36,101,1987.

[15]A.D.Vyas, V.A.Rana, S.C. Mehrotra, Dielectric relaxation study of mixtures of 1-propanol with aniline,2- chloroaniline and 3-

\section{AUTHORS PROFILE}

Mrs.RM.umamaheshwari (Reg No.
673/2012-13) Research Scholar Part time. She is currently pursuing her $\mathrm{Ph}$. D. degree at Alagappa University Karaikudi, India. She worked as Associate Professor of Physics, PG \& Research Department of Physics, Sree Sevugan Annamalai Devakottai - 630303.



Mr. K. Sathish kumar worked as a UGC project fellow under the supervision of Dr. M. Subramanian, after he pursued his M. Phil. degree from Alagappa University, Karaikudi. chloroaniline at different temperatures using time domain reflectometry J. Mol. Liqs, 102, 379, 2003.

[16]S.N. Helambe, Ajay Choudary, S.C. Mehrotra, Temperature dependent dielectric study of n-nitriles in methanol using time domain reflectometry, J. Mol. Liqs., 84, 235-244, 2000

[17]A.Chaudhari, , D.Anita, , G. Raju,H.Chaudhari, K.Prakash, Navinkumar, N.Suresh, M., Complex Permittivity Spectra of Binary Mixture of Ethanol with Nitrobenzene and Nitrotoluene Using the Time Domain Technique, Proc. Natl. Sci. Counc., Roc., No. 4, A25 , 205-210, 2001.

[18]S. Kumar, L. Guganathan, M. Malathi, A.Mohan, R. Amalanathan, Dielectric Relaxation studies of Methyl acetate with 2Alkoxyethanols using Time Domain Reflectometry Technique, International Journal of Scientific Research in Physics and Applied SciencesVol.6, Issue.5, pp.27-40, 2348-3423, Oct, 2018.

[19]D.Balamurugan, S.Kumar, S.Krishnan, Dielectric relaxation studies of higher order alcohol complexes with amines using time domain reflectometry,J. Mol.Liq., 122, 11-14, 2005.

[20 M.T. Hosamani, R.H. Fattepur, D.K. Dhaspande, S.C. Mehrotra, Temperature-and frequency-dependent dielectric studies of $\mathrm{p}$ fluorophenylacetonitrile-methanol mixtures using time-domain reflectometry J. Chem. Soc.Faraday Trans., 91(4), 623, 1995.

[21]A.Ghanadzadeh, H.Ghanadzadeh, M.Alinejad, Dielectric Study on Polar Binary Mixtures of (Ester-Alcohol) at 298.2 K J.Chem. Eng., 9, 3, 2012.

[22]Varadarajan, R., and Rajagopal, A., Dipolar excess thermodynamic parameters and kirkwood-frohlich correlation factor of monoalcohols, Ind.J.Pure, Appl.Phys., 36,113-118, 1998.

[23]K. Dharmalingam, K. Ramachandran, P.Sivagurunathan, B . Prabhakar Undre, P.W.Khirade, S.C. Mehrotra, Dielectric Relaxation of Binary Mixtures of Alcohols with Ethyl Methacrylate Tam. J.Sci., Eng., 12 ,123-128, 2009.

[24]Thenappan, T. and Sankar, U., Dielectric of hydrogen bonded complexes of alcohols with $\mathrm{NN}$-dimethyl formamide, J. Mol. Liqs., 126, 38-42, 2006.

[25]P. Sivagurunathan, K. Dharmalingam, K.Ramachandran, U. B. Prabhakar P.W.Khirade, S. C. Mehrotra, Dielectric studies on binary mixtures of ester with alcohol using time domain reflectometry, J. Mol. Liq. 133, 139-145, 2007

Dr. M. Subramanian pursed Bachelor of Science, Master of Science (Physics), and Ph.D., in Physics from Alagappa University Karaikudi, India. He is currently working as Dean (Research) in Fatima Michael College of Engg. \& Tech., Madurai, Tamilnadu, India.

Previously, he worked as Head of the

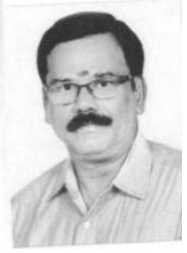
Department of Physics, Sree Sevugan Annamalai College, Devakottai - 630 303. He has more than 25 publications in international refereed journals with high impact factors in the area of Dielectric materials. He is having 40 years of teaching experience. 